\title{
A specific subtype of chronic obstructive pulmonary disease classified by forced vital capacity
}

\author{
Chunlan Chen ${ }^{1 \#}$, Ying He ${ }^{2 \#}$, Qiulin Chen ${ }^{1}$, Dongying Zhang ${ }^{1}$, Yuandi Wang ${ }^{1}$, Yanling Tang ${ }^{1}$, Ying Fang ${ }^{1}$, \\ Nanshan Zhong ${ }^{1}$, Wenhua Jian ${ }^{1}$, Jinping Zheng ${ }^{1}$ \\ ${ }^{1}$ State Key Laboratory of Respiratory Disease, National Clinical Research Center for Respiratory Disease, Guangzhou Institute for Respiratory \\ Health, First Affiliated Hospital of Guangzhou Medical University, Guangzhou 510120, China; ${ }^{2}$ Department of Gastroenterology, Xiangya Hospital, \\ Central South University, Changsha 410008, China \\ Contributions: (I) Conception and design: C Chen, W Jian, J Zheng, N Zhong; (II) Administrative support: None; (III) Provision of study materials \\ or patients: None; (IV) Collection and assembly of data: C Chen, W Jian, Q Chen, D Zhang, Y Wang, Y Tang, Y Fang; (V) Data analysis and \\ interpretation: C Chen, Y He; (VI) Manuscript writing: All authors; (VII) Final approval of manuscript: All authors. \\ \#These authors contributed equally to this study. \\ Correspondence to: Jinping Zheng, MD; Wenhua Jian, PhD. State Key Laboratory of Respiratory Disease, National Clinical Research Center of \\ Respiratory Disease, Guangzhou Institute for Respiratory Health, First Affiliated Hospital of Guangzhou Medical University, 151 Yanjiang Road, \\ Guangzhou, Guangdong 510120, China. Email: jpzhenggy@163.com; jian-wenhua@163.com.
}

Background: Forced expiratory volume in one second $\left(\mathrm{FEV}_{1}\right)$ is widely used in grading the severity of the airflow limitation observed in chronic obstructive pulmonary disease (COPD). However, the characteristics of COPD classified by forced vital capacity (FVC) remain unknown. Hence, the characteristics of pulmonary function test (PFT) and clinical features of COPD patients classified by FVC were investigated.

Methods: COPD patients were classified into three groups by FVC: (I) large consistent FVC (LC-FVC): before bronchodilator (BBD) and after bronchodilator (ABD) FVC $\geq 80 \%$ pred; (II) inconsistent FVC (I-FVC): BBD FVC $<80 \%$ pred, while ABD FVC $\geq 80 \%$ pred; (III) small consistent FVC (SC-FVC): BBD and ABD FVC $<80 \%$ pred. The characteristics of pulmonary function and clinical features of 1,329 retrospective patients and 403 prospective patients were analyzed in different FVC subgroups.

Results: The percentages of LC-FVC, I-FVC and SC-FVC were 25.4\%, $13.8 \%$ and 60.9\%, respectively in the retrospective cohort, and were $34.0 \%, 15.6 \%, 50.4 \%$, respectively in the prospective cohort. For the 1,329 retrospective patients, I-FVC showed the best responsiveness to bronchodilator when compared with those of LC-FVC and SC-FVC, no matter evaluated by $\mathrm{FEV}_{1}(0.21$ vs. 0.14 vs. $0.10 \mathrm{~L}, \mathrm{P}<0.001)$ or FVC ( 0.47 vs. 0.15 vs. $0.23 \mathrm{~L}, \mathrm{P}<0.001$ ), and similar results were found in the 403 prospective patients. Of the 405 retrospective patients who finished lung volume tests, I-FVC and SC-FVC demonstrated higher residual volume than that of LC-FVC (3.43 vs. 3.15 vs. $2.89 \mathrm{~L}, \mathrm{P}<0.05)$, while I-FVC and LC-FVC showed higher total lung capacity than that of SC-FVC $(5.92$ vs. 6.06 vs. $5.18 \mathrm{~L}, \mathrm{P}<0.05)$. In the prospective cohort, LC-FVC and I-FVC experienced more asthma comorbidity than that of SC-FVC $(30.7 \%$ vs. $30.2 \%$ vs. $16.7 \%, \mathrm{P}=0.005)$; I-FVC group tended to experience more exacerbation events than the other two groups (1.7 vs. 1.2 vs. $1.5, \mathrm{P}=0.114$ ).

Conclusions: COPD patients classified by BBD and ABD FVC showed obviously different clinical characteristics, which could assist in distinguishing I-FVC patients who may benefit most from bronchodilators.

Keywords: Global initiative for chronic obstructive lung disease (GOLD); bronchodilator responsiveness; lung volumes; treatment

Submitted Apr 24, 2018. Accepted for publication Nov 30, 2018.

doi: $10.21037 /$ jtd.2018.12.06

View this article at: http://dx.doi.org/10.21037/jtd.2018.12.06 


\section{Introduction}

Chronic obstructive pulmonary disease (COPD) is a chronic disease characterized by persistent respiratory symptoms and airflow limitation (1). Spirometric measurement of an after-bronchodilator (ABD) forced expiratory volume in one second to forced vital capacity ratio $\left(\mathrm{FEV}_{1} / \mathrm{FVC}\right)$ $<0.7$ confirms the presence of persistent airflow limitation. Airflow limitation leads to a decreased $\mathrm{FEV}_{1}$, which is used to grade airflow limitation severity into global initiative for chronic obstructive lung disease (GOLD) stages 1-4 (1). $\mathrm{FEV}_{1}$ is extensively applied in the aspects of COPD, including disease severity evaluation, bronchodilators reversibility estimation, and exacerbation prediction (1-3). However, $\mathrm{FEV}_{1}$ is poorly associated with symptoms, impairment of a patient's health status and may not be a reliable descriptor of disease status for $\operatorname{COPD}(1,4,5)$.

Besides $\mathrm{FEV}_{1}, \mathrm{FVC}$ is another critical spirometric indicator. FVC is a volume parameter, which improves more significantly than $\mathrm{FEV}_{1}$ after inhalation of bronchodilator and identified a larger percentage of patients with significant responsiveness (6-8). Except for decreased $\mathrm{FEV}_{1}$ and $\mathrm{FEV}_{1} /$ $\mathrm{FVC}$, descending FVC is another common lung function manifestation in COPD. The obstruction of airway and the loss of lung recoil contribute to the increase in total lung capacity (TLC), while a decreased FVC results in an increasing residual volume (RV), which leads to the pathophysiologic condition of lung hyperinflation (9). Lung hyperinflation is associated with increased dyspnea, limitation of exercise capacity and frequent exacerbations (9-11). Therefore, identifying patients who have significant improvement of FVC will bring important clinical implications.

In clinical practice, some COPD patients show large before bronchodilator (BBD) FVC [FVC $\geq 80 \%$ predicted value $(80 \%$ pred)] while others show small BBD FVC (FVC $<80 \%$ pred). For those with small BBD FVC, part of them reach large ABD FVC (FVC $\geq 80 \%$ pred), while some remain persistent small ABD FVC (FVC $<80 \%$ pred). Moreover, the clinical features of patients with different FVC patterns are unclear. Thus, in the present study, 1,329 COPD patients were retrospectively included and 403 COPD patients were prospectively enrolled to explore the pulmonary function tests (PFT) characteristics and clinical features of patients with different FVC patterns.

\section{Methods}

\section{Patients}

Thirteen twenty-nine outpatients with stable COPD were retrospectively included, who were diagnosed by pulmonary physicians in the First Affiliated Hospital of Guangzhou Medical University between January 2011 and June 2015. All included participants met the following criteria: age $\geq 40$ years; $\mathrm{ABD} \mathrm{FEV}_{1} / \mathrm{FVC}<0.7$; respiratory symptoms keep stable and without respiratory infection within the last 4 weeks. Non-inclusion criteria were as following: a history of pulmonary resection or significant diseases other than COPD that might influence the patients to perform PFT. All the included 1,329 patients performed bronchodilation tests and 405 of them performed lung volume tests before bronchodilation tests. Patients who finished lung volume tests have been the subjects of previous study on different aspects (8).

Four hundred and three COPD patients were prospectively included from outpatient clinic of the First Affiliated Hospital of Guangzhou Medical University between February 2016 and July 2017. The inclusion criteria and non-inclusion criteria referred to those of retrospective patients. Data were collected by trained and skilled physicians or technicians, majorly involved demographics (age, sex, height and weight), medical history (including symptoms, particle exposure status and course of disease), bronchodilation test records, questionnaires [COPD assessment test (CAT) (12) and the modified Medical Research Council (mMRC)] Dyspnea Scale (13), exacerbation history, comorbidities and medication history.

This study was approved by the First Affiliated Hospital of Guangzhou Medical University Ethics Committee. Written informed consent of PFT was obtained from all patients prior to the test, and all prospective patients gave written informed consent to participate. All patient information was kept confidential.

\section{PFT}

Equipment (Jaeger Masterscreen Body, BD, Germany; Cosmed Quark PFT, COSMED, Italy) met the criteria of the American thoracic society and the European respiratory society $(14,15)$. Before PFT, patients were required to 
withdraw short- and long-acting bronchodilators (for $\geq 6$ and $\geq 24$ hours, respectively), short- and long-acting theophylline (for $\geq 24$ and $\geq 48$ hours, respectively), antileukotrienes (for $\geq 48$ hours), and avoid smoking, exercise, and tea/coffee (for $\geq 4$ hours).

Lung volumes (RV and TLC) were randomly tested by body plethysmograph method or multiple-breath $\mathrm{N}_{2}$ washout method, which were described previously (8). After lung volume test, spirometries were performed before and 20-30 minutes after inhaling $400 \mu \mathrm{g}$ salbutamol via metered dose inhaler. Predicted values of FVC and FEV were selected from the reference values for spirometry in Chinese population (16).

COPD patients were classified into GOLD stages 1 -4 based on the ABD FEV ${ }_{1}$ : stage $1: \mathrm{FEV}_{1} \geq 80 \%$ pred; stage 2: $50 \%$ pred $\leq \mathrm{FEV}_{1}<80 \%$ pred, stage $3: 30 \%$ pred $\leq \mathrm{FEV}_{1}$ $<50 \%$ pred, stage $4: \mathrm{FEV}_{1}<30 \%$ pred (1). Patients were divided into three groups according to the measurements of BBD and ABD FVC: (I) large consistent FVC group (LC-FVC): with $\mathrm{BBD}$ and $\mathrm{ABD}$ FVC $\geq 80 \%$ pred; (II) inconsistent FVC group (I-FVC): with BBD FVC $<80 \%$ pred, while $\mathrm{ABD} F \mathrm{FVC} \geq 80 \%$ pred; (III) small consistent FVC group (SC-FVC): with BBD and ABD FVC $<80 \%$ pred. Moreover, lower limit of normal (LLN) of Chinese reference value (16) was used to define patients into three groups: (I) normal FVC group (N-FVC): with $\mathrm{BBD}$ and $\mathrm{ABD} F V C \geq \mathrm{LLN}$; (I) inconsistent FVC group (IC-FVC): with BBD FVC $<$ LLN, but ABD FVC $\geq$ LLN; (III) limited FVC group (L-FVC): with BBD and ABD $\mathrm{FVC}<\mathrm{LLN}$.

\section{Statistical analysis}

Data were analyzed using SPSS 18.0 software (SPSS Inc., Chicago, IL, USA). Variables were presented as mean \pm standard deviation (SD) or as proportions unless otherwise specified. Categorical variables were analyzed by Chi-square test or Fisher's exact test. Variables showed normal distribution were analyzed by unpaired $t$-test or analysis of variance (ANOVA), and Student's-NewmanKeuls tests or Tamhane's T2 tests were further used for multiple comparison tests when significant differences among all groups were found. Variables not showing normal distribution were analyzed by Kruskal-Wallis test, followed by multiple comparisons among groups with the non-parametric Mann-Whitney U test. Receiver operating characteristic curve (ROC) was performed for selecting cutoff value of the improvement of FVC to detect I-FVC subtype. $\mathrm{P}<0.05$ was considered as statistically significant.

\section{Results \\ Population characteristics}

For the 1,329 retrospective patients, the mean age was $66.3 \pm 8.4$ years, $90.5 \%$ of patients were men. And $4.7 \%$, $28.1 \%, 42.4 \%$ and $24.8 \%$ of patients were classified in GOLD stages 1, 2, 3 and 4, respectively. A total of 403 patients were prospectively enrolled in the present study. They were similar to retrospective patients in sex and GOLD stages distributions, but body mass index (BMI), age, smoking history and some PFT variables differed within these two groups. The patients' demographics and baseline characteristics were presented in Table 1 .

\section{Characteristics of bronchodilation test}

For total 1,329 retrospective patients, 987 (74.3\%) had BBD FVC $<80 \%$ pred, and only 804 (60.5\%) had ABD FVC $<80 \%$ pred, which indicated an improvement of FVC ABD. The mean improvements of FVC $(\triangle \mathrm{FVC}, \mathrm{L})$ from GOLD stages 1 to 4 were $0.10,0.21,0.27,0.27$, respectively. The remarkable improvements of FVC existed in GOLD stages 3-4. While the mean improvements of $\mathrm{FEV}_{1}\left(\triangle \mathrm{FEV}_{1}\right.$, L) from GOLD stages 1 to 4 were $0.15,0.15,0.13,0.07$, respectively. These results suggested that improvements of $\mathrm{FEV}_{1}$ decreased across GOLD stages.

When FVC classification method was used, for the 1,329 retrospective patients, 337 (25.4\%) patients met the criteria of LC-FVC group. Seventy-two point seven percent of the LC-FVC patients distributed in GOLD stages 1-2 (Table 1). One hundred eighty-three (13.8\%) patients were included in I-FVC group, $91.2 \%$ of the I-FVC patients distributed in GOLD stages 2-3. Eight hundred and nine (60.9\%) patients met the criteria of SC-FVC group, $86.9 \%$ of the SC-FVC patients distributed in GOLD stages 3-4. The $\triangle \mathrm{FVC}(\mathrm{L})$ of LC-FVC, I-FVC and SC-FVC groups were $0.15 \pm 0.23,0.47 \pm 0.27$ and $0.23 \pm 0.22$, respectively $(\mathrm{P}<0.001)$; and corresponding $\triangle \mathrm{FEV}_{1}(\mathrm{~L})$ were $0.14 \pm 0.14,0.21 \pm 0.13$ and $0.10 \pm 0.09$, respectively $(\mathrm{P}<0.001)$ (Figure 1$)$. I-FVC group showed the best improvements in both FVC and $\mathrm{FEV}_{1}$, especially in FVC.

The percentages of LLN defined N-FVC, IC-FVC and L-FVC were $23.6 \%, 13.3 \%$ and $63.1 \%$, which were similar to the distribution classified by fixed $80 \%$ pred. Meanwhile, the best improvements of $\mathrm{FEV}_{1}$ and $\mathrm{FVC}$ (in L) were also 


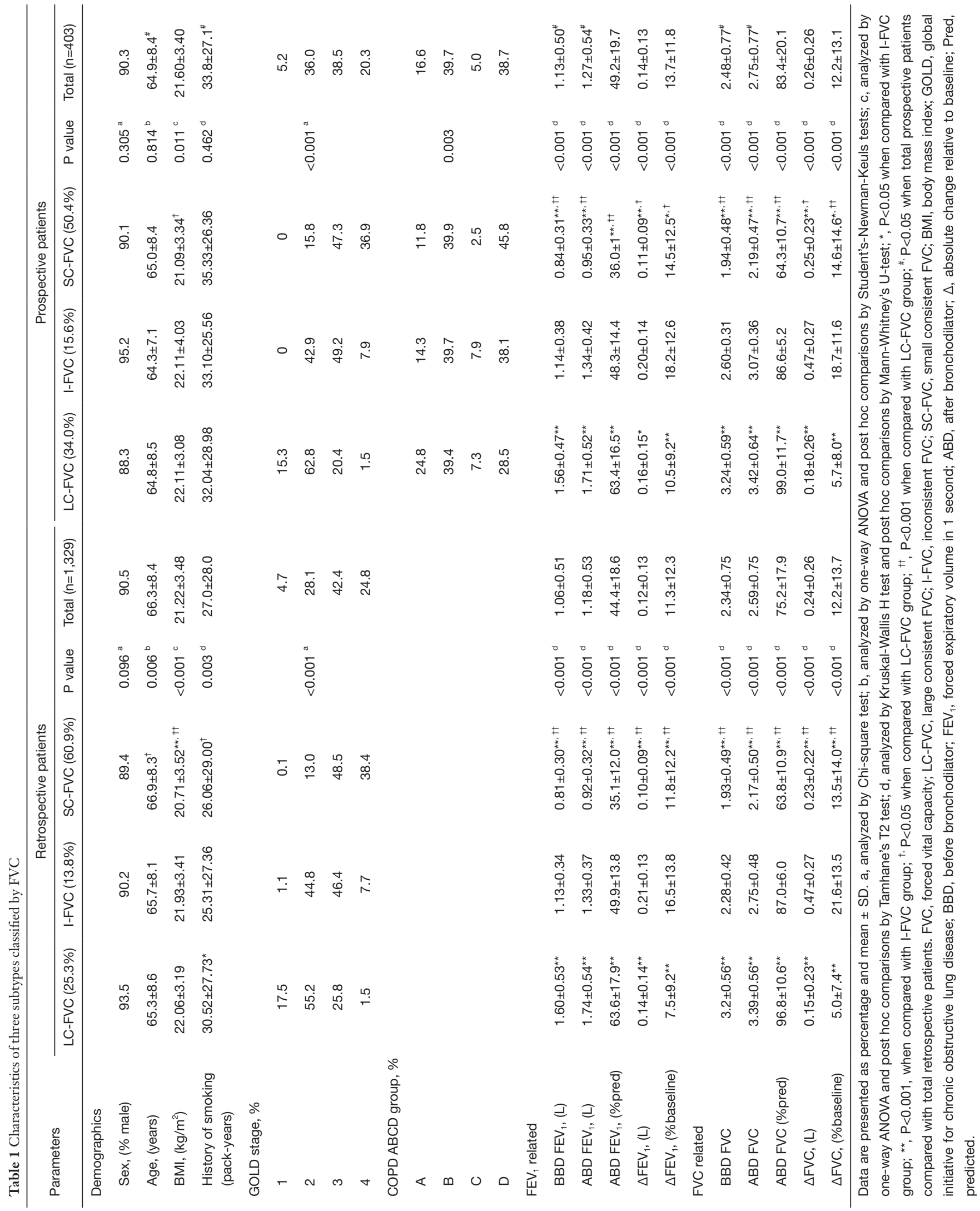



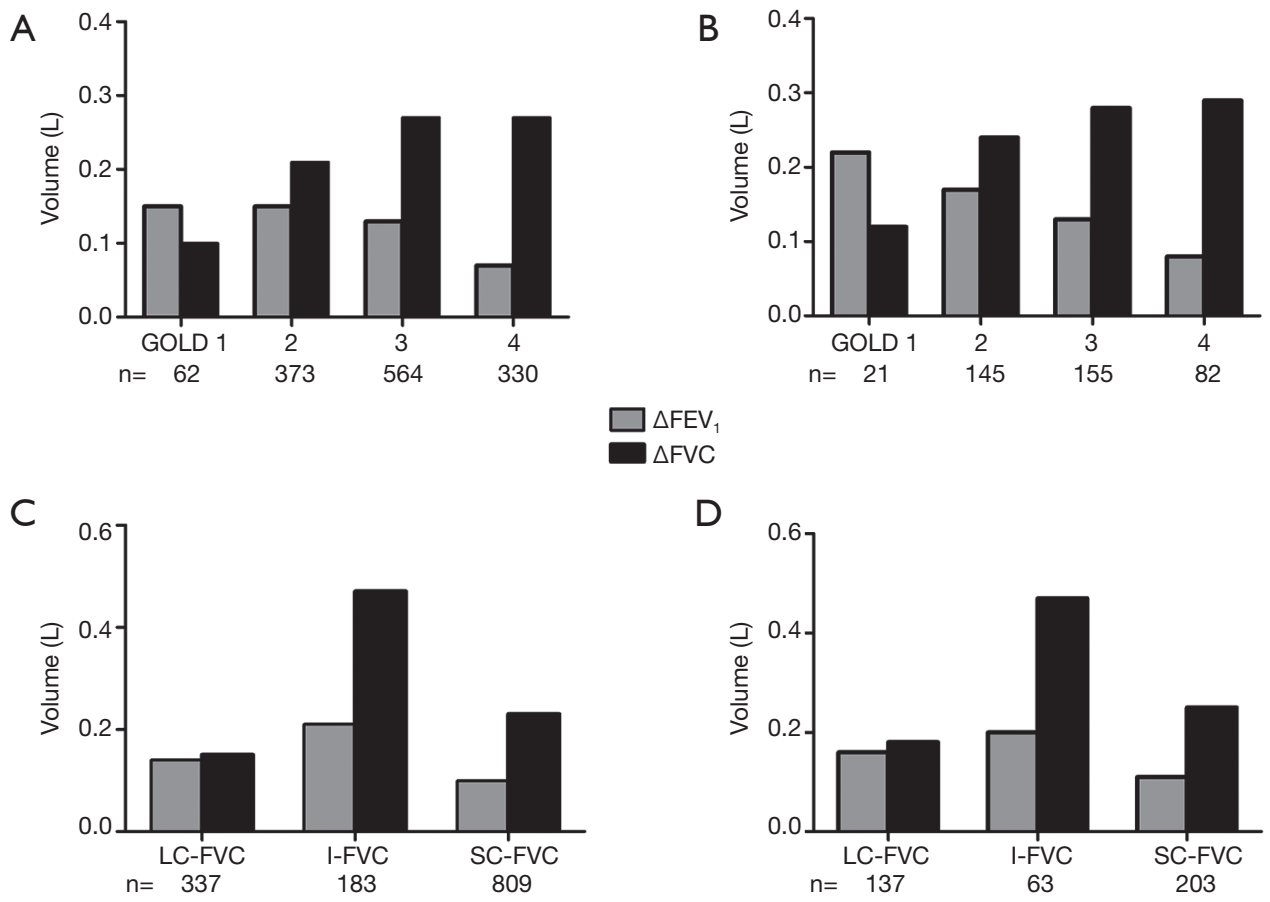

$\square \triangle \mathrm{FEV}_{1}$

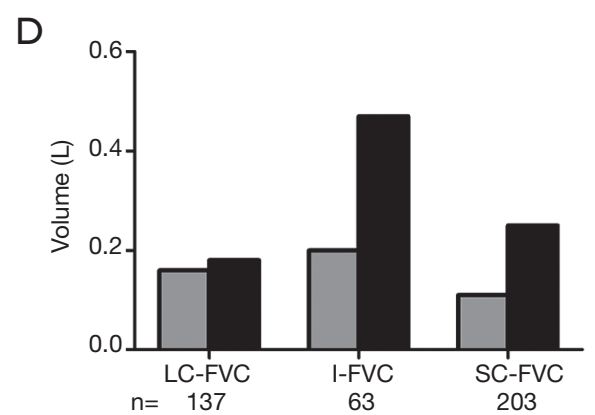

Figure 1 Improvements of $\mathrm{FEV}_{1}$ and FVC in different subgroups. The improvements of $\mathrm{FEV}_{1}$ and FVC in GOLD stages $1-4$ from retrospective patients $(n=1,329)(A)$ and prospective patients $(n=403)(B) . \Delta F V C$ increased across $G_{\text {OLD stages while } \Delta F E V}$ decreased across GOLD stages. The improvements of $\mathrm{FEV}_{1}$ and FVC in patients classified by FVC from retrospective patients (n=1,329) $(\mathrm{C})$ and prospective patients $(\mathrm{n}=403)$ (D). Both $\triangle \mathrm{FVC}$ and $\triangle \mathrm{FEV}_{1}$ were largest in I-FVC group. GOLD, global initiative for chronic obstructive lung disease; $\mathrm{FEV}_{1}$, forced expiratory volume in 1 second; FVC, forced vital capacity; $\Delta$, absolute change relative to baseline; LC-FVC, large consistent FVC; I-FVC, inconsistent FVC; SC-FVC, small consistent FVC.

existed in IC-FVC group $\left(\triangle \mathrm{FEV}_{1}: 0.21 ; \triangle \mathrm{FVC}: 0.48\right)$ rather than N-FVC group $\left(\Delta \mathrm{FEV}_{1}: 0.14 ; \Delta \mathrm{FVC}: 0.14\right)$ or L-FVC group $\left(\Delta \mathrm{FEV}_{1}: 0.10 ; \Delta \mathrm{FVC}: 0.23\right)$ (Table $\left.S 1\right)$.

As Table 1, Figure 1 and Table 1 shown, the FVC group distribution and bronchodilator responsiveness for 403 prospective patients were similar to those of retrospective ones.

Asthma is thought to be a factor influencing the responsiveness of lung function parameter to bronchodilator. Hence, 403 prospective patients were further stratified by with asthma or free from asthma and then performed for FVC classification analysis. Interestingly, patients in I-FVC group showed the best responsiveness to bronchodilator no matter patients with asthma $\left(\triangle \mathrm{FEV}_{1}: 0.29\right.$ vs. 0.20 vs. $0.14 \mathrm{~L}$, $\mathrm{P}=0.002 ; \Delta \mathrm{FVC}: 0.62$ vs. 0.21 vs. $0.34 \mathrm{~L}, \mathrm{P}<0.001)$ or free from asthma $\left(\Delta \mathrm{FEV}_{1}: 0.15\right.$ vs. 0.14 vs. $0.10 \mathrm{~L}, \mathrm{P}=0.004$; $\Delta$ FVC: 0.41 vs. 0.17 vs. $0.23 \mathrm{~L}, \mathrm{P}<0.001)$ when compared to those of LC-FVC group and SC-FVC group (Table S2).

\section{Characteristics of lung volume tests}

For the 405 retrospective patients who finished lung volume tests, 317 (78.2\%) patients were performed using multiple-breath $\mathrm{N}_{2}$ washout method while 88 (21.8\%) patients by body plethysmograph method. As Figure 2 shown, the RV (L) of LC-FVC, I-FVC and SC-FVC groups by multiple-breath $\mathrm{N}_{2}$ washout method were 2.89, 3.4 and $3.15(\mathrm{P}<0.001)$, respectively, and by body plethysmograph method were 3.68, 4.66 and $4.42(\mathrm{P}=0.002)$, respectively. The RV in I-FVC group and SC-FVC group were significantly larger than that in LC-FVC group by two measurement methods. The TLC (L) in LC-FVC, I-FVC and SC-FVC groups by multiple-breath $\mathrm{N}_{2}$ washout method were 6.06, 5.92 and $5.18(\mathrm{P}<0.001)$, respectively, and by body plethysmograph method were $6.74,7.25$ and $6.58(\mathrm{P}=0.176)$, respectively. TLC were larger in I-FVC group than that SC-FVC group by multiple-breath $\mathrm{N}_{2}$ 

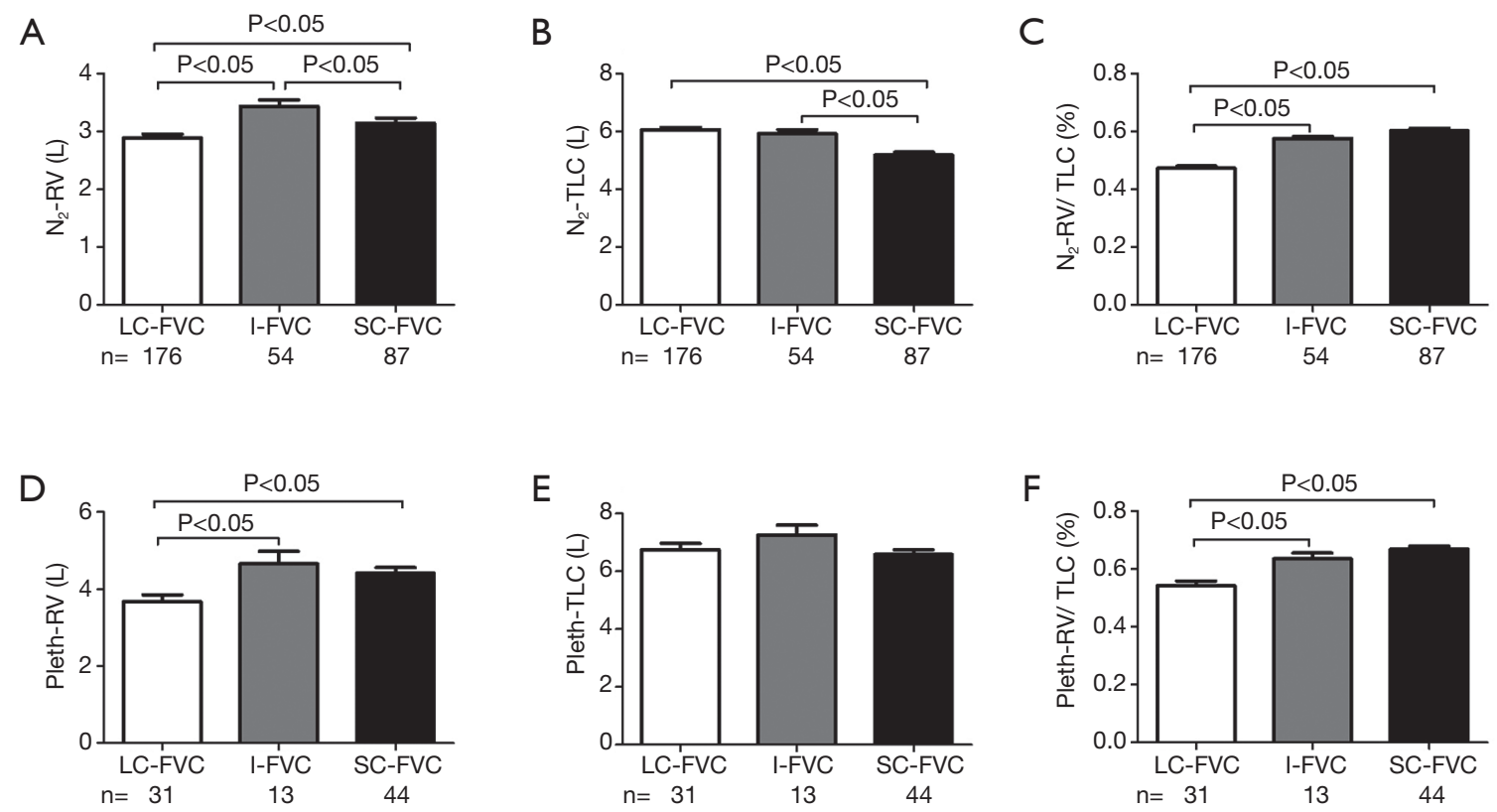

Figure 2 Average RV, TLC and RV/TLC of varying FVC groups. (A-C) RV, TLC and RV/TLC in FVC groups measured by multiplebreath $\mathrm{N}_{2}$ washout method; (D-F) RV, TLC and RV/TLC in FVC groups measured by plethysmograph method. RV is largest in I-FVC group, TLC is smallest in SC-FVC group and RV/TLC is largest in SC-FVC group no matter measured by multiple-breath $\mathrm{N}_{2}$ washout method or by plethysmograph method. RV, residual volume; TLC, total lung capacity; FVC, forced vital capacity; LC-FVC, large consistent FVC; I-FVC, inconsistent FVC; SC-FVC, small consistent FVC. $\mathrm{N}_{2}$, multiple-breath $\mathrm{N}_{2}$ washout method; Pleth, plethysmograph method.

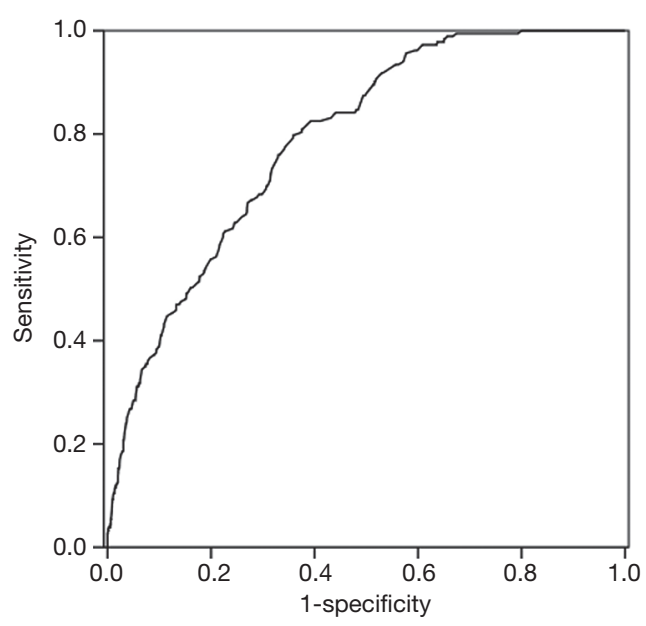

Figure 3 Receiver operating characteristic curve for $\triangle \mathrm{FVC}$ to detect I-FVC patients. $\Delta$, absolute change relative to baseline; FVC, forced vital capacity; I-FVC, inconsistent FVC classified by fixed $80 \%$ predicted value.

washout method $(\mathrm{P}<0.05)$ and plethysmograph method (P>0.05). The RV/TLC in LC-FVC, I-FVC and SC-FVC groups were $0.47,0.58$ and $0.60(\mathrm{P}<0.001)$, respectively, by multiple-breath $\mathrm{N}_{2}$ washout method and were $0.54,0.63$ and $0.67(\mathrm{P}<0.001)$, respectively, by body plethysmograph method. The RV/TLC ratio increased from LC-FVC to SC-FVC group. These results were consistent in body plethysmograph method and multiple-breath $\mathrm{N}_{2}$ washout method.

\section{Cut-off value of the improvement of FVC to detect I-FVC group}

The ROC curve was used to test the ability of $\triangle \mathrm{FVC}$ to predict a presence of I-FVC. The area under the ROC curve (AUC) for $\triangle \mathrm{FVC}$ was $0.79(\mathrm{P}<0.001)$. The cut-off value for $\triangle \mathrm{FVC}$ was $0.27 \mathrm{~L}$ with the best sensitivity (80.0\%) and specificity (64.1\%) (Figure 3).

\section{Clinical results of the prospective patients}

As Table 2 shown, the CAT and mMRC scores increased from LC-FVC, I-FVC to SC-FVC (CAT score: 11.4 \pm 6.4 , $12.8 \pm 6.9$ and $14.6 \pm 6.8, \mathrm{P}<0.001 ; \mathrm{mMRC}$ score: $1.3 \pm 0.9$, $1.5 \pm 0.8$ and $1.9 \pm 0.8, \mathrm{P}<0.001)$. I-FVC group tended to show higher exacerbation frequency than that of LC-FVC and 
Table 2 Clinical characteristics of 403 prospective patients classified by FVC

\begin{tabular}{|c|c|c|c|c|}
\hline Parameters & LC-FVC (34.0\%) & I-FVC (15.6\%) & SC-FVC (50.4\%) & $P$ value \\
\hline mMRC scores & $1.3 \pm 0.9$ & $1.5 \pm 0.8$ & $1.9 \pm 0.8^{*,+\dagger}$ & $<0.001^{a}$ \\
\hline $\begin{array}{l}\text { Exacerbation frequencies in the } \\
\text { previous year }\end{array}$ & $1.2 \pm 1.6$ & $1.7 \pm 2.4$ & $1.5 \pm 1.9$ & $0.114^{a}$ \\
\hline \multicolumn{5}{|l|}{ Comorbidities } \\
\hline Asthma & $42(30.7 \%)$ & $19(30.2 \%)$ & $34(16.7 \%)$ & $0.005^{b}$ \\
\hline Bronchiectasis & $13(9.5 \%)$ & $5(7.9 \%)$ & $28(13.8 \%)$ & $0.302^{b}$ \\
\hline \multicolumn{5}{|l|}{ Medications } \\
\hline LABA & $31(22.6 \%)$ & $12(19.0 \%)$ & $41(20.2 \%)$ & $0.803^{b}$ \\
\hline ICS & $30(21.9 \%)$ & $12(19.0 \%)$ & $42(20.7 \%)$ & $0.897^{b}$ \\
\hline
\end{tabular}

Data are presented as mean \pm SD and number (percentage). a, analyzed by Kruskal-Wallis $\mathrm{H}$ test and post hoc analysis by Mann-Whitney's U-test; b, analyzed by Chi-square test; ${ }^{*}, \mathrm{P}<0.05$ when compared with I-FVC group; ${ }^{\dagger}, \mathrm{P}<0.05$ when compared with LC-FVC group. FVC, forced vital capacity; LC-FVC, large consistent FVC; I-FVC, inconsistent FVC; SC-FVC, small consistent FVC; CAT, COPD assessment test; mMRC, modified medical research council score; SABA, short-acting $\beta_{2}$-agonist; SAMA, short-acting muscarinic antagonist; LAMA, long-acting muscarinic antagonist; LABA, long-acting $\beta_{2}$-agonist; ICS, inhaled corticosteroids.

SC-FVC group but without statistical significance $(1.7 \pm 2.4$ vs. $1.2 \pm 1.6$ vs. $1.5 \pm 1.9, \mathrm{P}=0.114)$. Remarkably, $\mathrm{LC}-\mathrm{FVC}$ and I-FVC groups presented a comparable higher proportion of $(30.7 \%$ and $30.2 \%)$ asthma comorbidity than that of SCFVC group (16.7\%). The other common comorbidities showed no differences within groups (Table S3). Medication use among the three groups showed no significant differences (Table 2).

\section{Discussion}

$\mathrm{FEV}_{1}$ is one of the most commonly used parameter for patients with COPD, while in the present study, patients with COPD were classified by a new category method according to BBD and ABD FVC. Patients with I-FVC presented higher RV and higher TLC; and had higher asthma and exacerbation frequencies. Importantly, I-FVC group demonstrated the better responsiveness to bronchodilator evaluated by both $\mathrm{FEV}_{1}$ and $\mathrm{FVC}$ among groups.

COPD usually progressively develops and its pulmonary function lost at an abnormal rate with annual decline in
$\mathrm{FEV}_{1}>40 \mathrm{~mL}$ per year (17). In GOLD guideline, patients are graded into GOLD stages 1 to 4 by $\mathrm{ABD} \mathrm{FEV}_{1}$ (1). In this study, more than $70 \%$ of LC-FVC patients existed in GOLD stages 1 and 2, and a majority of I-FVC patients belonged to GOLD stages 2 and 3, while SC-FVC patients majorly existed in GOLD stages 3 and 4. Therefore, it is logically considered that COPD patients classified by FVC (from LC-FVC to SC-FVC) show the progressive development of COPD, similar to GOLD stages classified by $\mathrm{FEV}_{1}$. Previous studies showed $\triangle \mathrm{FVC}$ increased across GOLD stages, while $\triangle \mathrm{FEV}_{1}$ decreased across GOLD stages during bronchodilation test $(6,7)$. In I-FVC patients, however, the improvements of both $\mathrm{FVC}$ and $\mathrm{FEV}_{1}$ were significantly larger than those of LC-FVC and SC-FVC patients. The tendency of bronchodilator responsiveness in FVC classification was different from that in $\mathrm{FEV}_{1}$ one.

Asthma-COPD overlap (ACO) have increased bronchodilator responsiveness than that of COPD alone (18). Thirty point two percent of the patients from I-FVC group are ACO, which partly influences the responsiveness to bronchodilator. While, interestingly, when analyses were confined to the patients free from asthma, I-FVC group 
still showed the best bronchodilator responsiveness among groups. Moreover, the $\triangle \mathrm{FVC}$ and $\triangle \mathrm{FEV}_{1}$ of LC-FVC group were less than those of I-FVC group though more (30.7\%) of the patients in LC-FVC were ACO. Hence, I-FVC is a special group which demonstrates the best bronchodilator responsiveness despite of the comorbidity of asthma.

$80 \%$ pred is a fixed threshold value ever been used to define normal FVC, and still been used in some countries including China. Considering $80 \%$ is convenient for clinical practice, it has been used to classify FVC groups in this study. Besides, in 2012, Global Lung Function Initiative (19) recommended multi-ethnic reference values for whole age (3-95 years) and provided LLNs to define normal pulmonary function. In the present study, FVC groups classified by LLN from Chinese population presented a similar bronchodilator responsiveness to groups classified by the fixed $80 \%$ pred. Therefore, FVC classification method can be widely used to identify patients who experience inconsistent FVC judged by either fixed $80 \%$ pred or LLN. A previous study found that many volume parameters did improve significantly better in the $\mathrm{FEV}_{1} \%$ pred $<65$ group than in the one with $\mathrm{FEV}_{1} \%$ pred $>65$ (20). These evidences indicate that COPD may has a special disease course or "break points", during which COPD patients response better to bronchodilators.

LC-FVC group were in the early stage of COPD disease with lower RV (2.89 L) and higher TLC (6.06 L), which allows a large baseline $\mathrm{FEV}_{1}$ and FVC. It was reasonable that less respiratory symptoms were seen in these patients. But it could not be ignored that many comorbidities existed in these patients, particularly asthma. Therefore, simultaneous managements of COPD and comorbidities were essential for these patients $(21,22)$.

I-FVC group showed higher RV (3.43 L) than LCFVC group and higher TLC $(5.92 \mathrm{~L})$ than SC-FVC group. The proportionate high TLC and high RV allow a relative moderate slow vital capacity $(\mathrm{VC})(=\mathrm{TLC}-\mathrm{RV})$ and symptoms $(10,23,24)$. Patients of I-FVC group were associated with a high prevalence of asthma and more frequent exacerbation events, which strongly suggested aggressive treatments were needed for these patients. Fortunately, patients of I-FVC with asthma or free from asthma both presented the best responsiveness to bronchodilators. Bronchodilators may improve $\mathrm{FEV}_{1}$ and $\mathrm{VC}$ and, therefore, lead to the decrease of RV, which tends to reduce hyperinflation at rest and during exercise and further improve exercise performance $(23,25,26)$ and reduce symptoms. Notably, for those patients who have asthma simultaneously, treatments with bronchodilator combined inhaled corticosteroid are needed (1).

SC-FVC majorly existed in GOLD stages 3 and 4. SC-FVC group showed higher RV $(3.15 \mathrm{~L})$ than LCFVC group but relative lower TLC $(5.18 \mathrm{~L})$ than the other groups, which leaded to a low $\mathrm{VC}$ and poor exercise tolerance. In this study, the high prevalence of past tuberculosis and bronchiectasis were seen in SC-FVC group, which might damage the lung parenchyma and/or airways. COPD patients with past tuberculosis is associated with decreased lung function and plays a role in the natural course of COPD (27). Additionally, the disease procession of COPD results in the narrowing of peripheral airways, loss of small airways and destruction of parenchyma, which contribute to decreased driving pressure for expiration and lead to airflow limitation and hyperinflation $(23,28,29)$. The FVC is disproportionately reduced compared with TLC, leading to the pathophysiological condition of lung hyperinflation. SC-FVC patients may need to overcome resistance before negative pressure can be created in the central airways to generate inspiratory flow, while which is contradictory with weakened respiratory muscles (BMI was significantly lowest in SC-FVC group). SC-FVC patients are apt to dynamic lung hyperinflation, which relates to dyspnea. Because of poor bronchodilator responsiveness, these patients require other treatments (like pulmonary rehabilitation) besides bronchodilators.

\section{Limitations}

The present study had some limitations. First, more than $90 \%$ of the patients were male in this study. The main reasons are listed as following: (I) males have a higher COPD prevalence $(11.9 \% ; 95 \%$ CI, $10.2-13.8)$ than do females (5.4\%; 95\% CI, 4.6-6.2; $\mathrm{P}<0.0001)$ (30); (II) smoking is the most popular risk factor for COPD in China, more than $70 \%$ male had smoking history while 7\% female did (30). Biomass exposure is the major risk factor for female COPD, who lived in rural area and had little awareness to hospital for disease detection and treatment. Second, among the 1,329 patients included in this study, only 405 patients finished PFT by either plethysmograph method ( $\mathrm{n}=88$ ) or multiple-breath $\mathrm{N}_{2}$ washout method $(\mathrm{n}=317)$. This imbalance derived from the fact that more multiple-breath $\mathrm{N}_{2}$ washout equipment were used in our PFT laboratory. But data from the two methods did not influence the interpretation of the results in this study. Third, some population characteristics differed within 
retrospective patients and prospective patients, even patients were randomly enrolled from outpatients. Besides some differences, findings in the two population cohorts were consistent, which indicated the characteristics of patients classified by FVC were constant. Fourth, this was a cross-sectional observational study, therefore the stability of FVC subtype, the treatment efficiency and exacerbation risks of different FVC groups remained unknown. Further prospective studies are needed to validate the clinical meaning of COPD subtypes classified by FVC.

\section{Conclusions}

In summary, this study putted forward new PFT subtypes of COPD according to BBD and ABD FVC, which showed obviously different lung volume conditions and responsiveness to bronchodilators. Classification of COPD into different FVC subtypes could assist in distinguishing I-FVC patients who may benefit better from bronchodilators.

\section{Acknowledgements}

Funding: This work was supported by the Guangzhou Healthcare Collaborative Innovation Major Project \#1 under Grant 201604020012; National Key Technology R\&D Program \#2 and \#3 under Grant 2017YFC1310601 and 2018YFC1311901.

\section{Footnote}

Conflicts of Interest: The authors have no conflicts of interest to declare.

Ethical Statement: This study was approved by the First Affiliated Hospital of Guangzhou Medical University Ethics Committee (No. 2016-45). Written informed consent of PFT was obtained from all patients prior to the test, and all prospective patients gave written informed consent to participate. All patient information was kept confidential.

\section{References}

1. Vogelmeier CF, Criner GJ, Martinez FJ, et al. Global Strategy for the Diagnosis, Management, and Prevention of Chronic Obstructive Lung Disease 2017 Report. GOLD Executive Summary. Am J Respir Crit Care Med 2017;195:557-82.
2. Tashkin DP, Celli B, Decramer M, et al. Bronchodilator responsiveness in patients with COPD. Eur Respir J 2008;31:742-50.

3. Hurst JR, Vestbo J, Anzueto A, et al. Susceptibility to exacerbation in chronic obstructive pulmonary disease. $\mathrm{N}$ Engl J Med 2010;363:1128-38.

4. Han MK, Muellerova H, Curran-Everett D, et al. GOLD 2011 disease severity classification in COPDGene: a prospective cohort study. Lancet Respir Med 2013;1:43-50.

5. Jones PW. Health status and the spiral of decline. COPD 2009;6:59-63.

6. Jian $\mathrm{W}$, Zheng J, Hu Y, et al. What is the difference between FEV1 change in percentage predicted value and change over baseline in the assessment of bronchodilator responsiveness in patients with COPD? J Thorac Dis 2013;5:393-9.

7. Zhang FQ, Zheng JP, Wang JH, et al. Comparison of lung volume response with airflow response to bronchodilator in patients with chronic obstructive pulmonary disease. Zhonghua Jie He He Hu Xi Za Zhi 2010;33:109-13.

8. Chen C, Jian W, Gao Y, et al. Early COPD patients with lung hyperinflation associated with poorer lung function but better bronchodilator responsiveness. Int J Chron Obstruct Pulmon Dis 2016;11:2519-26.

9. O'Donnell DE, Revill SM, Webb KA. Dynamic hyperinflation and exercise intolerance in chronic obstructive pulmonary disease. Am J Respir Crit Care Med 2001;164:770-7.

10. O'Donnell DE, Laveneziana P. Dyspnea and activity limitation in COPD: mechanical factors. COPD 2007;4:225-36.

11. Oh YM, Sheen SS, Park JH, et al. Emphysematous phenotype is an independent predictor for frequent exacerbation of COPD. Int J Tuberc Lung Dis 2014;18:1407-14.

12. Jones PW, Harding G, Berry P, et al. Development and first validation of the COPD Assessment Test. Eur Respir J 2009;34:648-54.

13. Fletcher CM. Standardised questionnaire on respiratory symptoms: a statement prepared and approved by the MRC Committee on the Aetiology of Chronic Bronchitis (MRC breathlessness score). BMJ 1960;2:1662.

14. Wanger J, Clausen JL, Coates A, et al. Standardisation of the measurement of lung volumes. Eur Respir J 2005;26:511-22.

15. Miller MR, Hankinson J, Brusasco V, et al. Standardisation of spirometry. Eur Respir J 2005;26:319-38. 
16. Jian W, Gao Y, Hao C, et al. Reference values for spirometry in Chinese aged $4-80$ years. J Thorac Dis 2017;9:4538-49.

17. Lange P, Celli B, Agusti A, et al. Lung-function trajectories leading to chronic obstructive pulmonary disease. N Engl J Med 2015;373:111-22.

18. Gibson PG, Simpson JL. The overlap syndrome of asthma and COPD: what are its features and how important is it? Thorax 2009;64:728-35.

19. Quanjer PH, Stanojevic S, Cole TJ, et al. Multi-ethnic reference values for spirometry for the 3-95-yr age range: the global lung function 2012 equations. Eur Respir J 2012;40:1324-43.

20. Jarenbäck L, Eriksson G, Peterson S, et al. Bronchodilator response of advanced lung function parameters depending on COPD severity. Int J Chron Obstruct Pulmon Dis 2016;11:2939-50.

21. Putcha N, Drummond MB, Wise RA, et al. Comorbidities and Chronic Obstructive Pulmonary Disease: Prevalence, Influence on Outcomes, and Management. Semin Respir Crit Care Med 2015;36:575-91.

22. Pearson M, Ayres JG, Sarno M, et al. Diagnosis of airway obstruction in primary care in the UK: the CADRE (COPD and Asthma Diagnostic/management REassessment) programme 1997-2001. Int J Chron

Cite this article as: Chen C, He Y, Chen Q, Zhang D, Wang Y, Tang Y, Fang Y, Zhong N, Jian W, Zheng J. A specific subtype of chronic obstructive pulmonary disease classified by forced vital capacity. J Thorac Dis 2018;10(12):6547-6556. doi: $10.21037 /$ jtd.2018.12.06
Obstruct Pulmon Dis 2006;1:435-43.

23. O'Donnell DE, Laveneziana P. The clinical importance of dynamic lung hyperinflation in COPD. COPD 2006;3:219-32.

24. Gibson GJ. Pulmonary hyperinflation a clinical overview. Eur Respir J 1996;9:2640-9.

25. O'Donnell DE, Fluge T, Gerken F, et al. Effects of tiotropium on lung hyperinflation, dyspnoea and exercise tolerance in COPD. Eur Respir J 2004;23:832-40.

26. O'Donnell DE, Sciurba F, Celli B, et al. Effect of fluticasone propionate/salmeterol on lung hyperinflation and exercise endurance in COPD. Chest 2006;130:647-56.

27. Yakar HI, Gunen H, Pehlivan E, et al. The role of tuberculosis in COPD. Int J Chron Obstruct Pulmon Dis 2017;12:323-9.

28. Hogg JC, Chu F, Utokaparch S, et al. The nature of smallairway obstruction in chronic obstructive pulmonary disease. N Engl J Med 2004;350:2645-53.

29. Rossi A, Aisanov Z, Avdeev S, et al. Mechanisms, assessment and therapeutic implications of lung hyperinflation in COPD. Respir Med 2015;109:785-802.

30. Wang C, Xu J, Yang L, et al. Prevalence and risk factors of chronic obstructive pulmonary disease in China (the China Pulmonary Health [CPH] study): a national cross-sectional study. Lancet 2018;391:1706-17. 
Table S1 Characteristics of three subtypes classified by lower limits of normal (LLN)

\begin{tabular}{|c|c|c|c|c|c|c|c|c|}
\hline \multirow{2}{*}{ Parameters } & \multicolumn{5}{|c|}{ Retrospective patients $(n=1,329)$} & \multicolumn{3}{|c|}{ Prospective patients $(n=403)$} \\
\hline & N-FVC (23.6\%) & IC-FVC (13.3\%) & L-FVC (63.1\%) & $P$ value & N-FVC (33.0\%) & IC-FVC (15.4\%) & L-FVC (51.6\%) & $P$ value \\
\hline \multicolumn{9}{|l|}{ Demographics } \\
\hline Sex, (\% male) & 93.3 & 89.8 & 89.6 & $0.159^{a}$ & 88.7 & 93.5 & 90.4 & $0.569^{a}$ \\
\hline Age, (years) & $65.5 \pm 8.4$ & $65.4 \pm 8.2$ & $66.7 \pm 8.2^{\dagger \dagger}$ & $0.034^{\mathrm{b}}$ & $64.9 \pm 8.4$ & $64.2 \pm 7.4$ & $65.0 \pm 8.4$ & $0.747^{\mathrm{b}}$ \\
\hline BMI, $\left(\mathrm{kg} / \mathrm{m}^{2}\right)$ & $22.12 \pm 3.16$ & $21.95 \pm 3.48$ & $20.74 \pm 3.50^{\star *,+\dagger}$ & $<0.001^{\mathrm{c}}$ & $22.13 \pm 3.10$ & $22.20 \pm 3.96$ & $21.08 \pm 3.34^{\dagger \dagger}$ & $0.006^{\circ}$ \\
\hline \multicolumn{9}{|l|}{ GOLD stage, $\%$} \\
\hline 1 & 18.8 & 1.1 & 0.1 & & 15.8 & 0.0 & 0.0 & \\
\hline 2 & 55.3 & 45.2 & 14.3 & $<0.001^{a}$ & 63.9 & 38.7 & 17.3 & $<0.001^{a}$ \\
\hline 3 & 24.3 & 48.6 & 47.9 & & 18.8 & 53.2 & 46.6 & \\
\hline 4 & 1.6 & 5.1 & 37.7 & & 1.5 & 8.1 & 36.1 & \\
\hline \multicolumn{9}{|l|}{ COPD ABCD group, \% } \\
\hline$A$ & & & & & 24.8 & 12.9 & 12.5 & \\
\hline $\mathrm{B}$ & & & & & 39.8 & 38.7 & 39.9 & $0.008^{a}$ \\
\hline $\mathrm{C}$ & & & & & 6.8 & 8.1 & 2.9 & \\
\hline $\mathrm{D}$ & & & & & 28.6 & 40.3 & 44.7 & \\
\hline \multicolumn{9}{|l|}{$\mathrm{FEV}_{1}$ related } \\
\hline $\mathrm{BBD} \mathrm{FEV}_{1},(\mathrm{~L})$ & $1.62 \pm 0.54^{\star *}$ & $1.14 \pm 0.33$ & $0.83 \pm 0.32^{* *,+\dagger}$ & $<0.001^{d}$ & $1.57 \pm 0.47^{\star *}$ & $1.11 \pm 0.36$ & $0.85 \pm 0.33^{* *,+\dagger}$ & $<0.001^{d}$ \\
\hline ABD FEV ${ }_{1},(L)$ & $1.76 \pm 0.55^{\star *}$ & $1.35 \pm 0.36$ & $0.93 \pm 0.34^{* *,+\dagger}$ & $<0.001^{d}$ & $1.73 \pm 0.52^{\star *}$ & $1.30 \pm 0.41$ & $0.97 \pm 0.35^{* *+\dagger}$ & $<0.001^{d}$ \\
\hline$\Delta \mathrm{FEV}_{1},(\mathrm{~L})$ & $0.14 \pm 0.14^{\star *}$ & $0.21 \pm 0.14$ & $0.10 \pm 0.11^{*,+\dagger \dagger}$ & $0.001^{d}$ & $0.16 \pm 0.15^{\star \star}$ & $0.20 \pm 0.14$ & $0.11 \pm 0.09^{\star \star, t \dagger}$ & $<0.001^{d}$ \\
\hline$\Delta \mathrm{FEV}_{1},(\%$ baseline $)$ & $8.0 \pm 7.6^{\star \star}$ & $15.5 \pm 9.3$ & $10.7 \pm 15.1^{*,+\dagger \dagger}$ & $<0.001^{d}$ & $10.2 \pm 9.1^{\star \star}$ & $18.7 \pm 12.8$ & $14.4 \pm 12.4^{* *, \dagger \dagger}$ & $<0.001^{d}$ \\
\hline \multicolumn{9}{|l|}{ FVC related } \\
\hline BBD FVC & $3.27 \pm 0.56^{\star \star}$ & $2.55 \pm 0.43$ & $1.96 \pm 0.50^{* *,+\dagger}$ & $<0.001^{d}$ & $3.25 \pm 0.59^{\star *}$ & $2.60 \pm 0.32$ & $1.96 \pm 0.49^{\star *,+\dagger}$ & $<0.001^{d}$ \\
\hline ABD FVC & $3.41 \pm 0.57^{* *}$ & $3.03 \pm 0.48$ & $2.19 \pm 0.51^{* *, \dagger \dagger}$ & $<0.001^{d}$ & $3.43 \pm 0.64^{\star *}$ & $3.09 \pm 0.37$ & $2.21 \pm 0.48^{\star \star,+\dagger}$ & $<0.001^{\mathrm{d}}$ \\
\hline$\Delta \mathrm{FVC},(\mathrm{L})$ & $0.14 \pm 0.23^{* \star}$ & $0.48 \pm 0.28$ & $0.23 \pm 0.23^{* *, \dagger \dagger}$ & $<0.001^{d}$ & $0.17 \pm 0.26^{\star *}$ & $0.49 \pm 0.26$ & $0.25 \pm 0.23^{* *+\dagger}$ & $<0.001^{d}$ \\
\hline$\Delta \mathrm{FVC},(\%$ baseline) & $4.7 \pm 7.1^{\star \star}$ & $19.8 \pm 12.9$ & $13.4 \pm 14.4^{\star *, \dagger \dagger}$ & $<0.001^{d}$ & $5.5 \pm 7.9^{\star \star}$ & $19.2 \pm 11.4$ & $14.5 \pm 14.4^{* *, \dagger \dagger}$ & $<0.001^{\mathrm{d}}$ \\
\hline
\end{tabular}

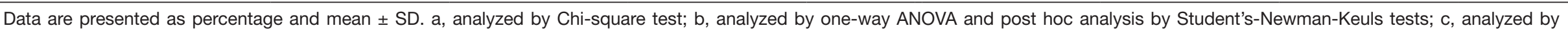

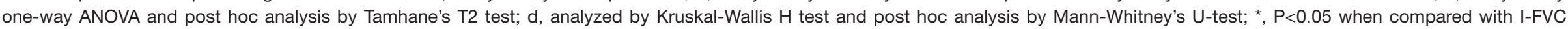

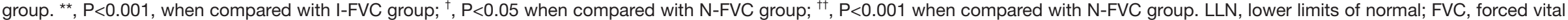

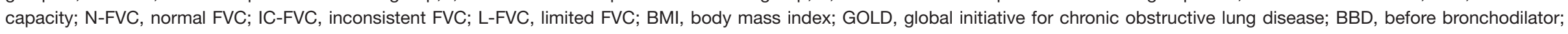
$\mathrm{FEV}_{1}$, forced expiratory volume in 1 second; $\mathrm{ABD}$, after bronchodilator; $\triangle$, absolute change relative to baseline. 
Table S2 Characteristics of subtypes classified by asthma and FVC

\begin{tabular}{|c|c|c|c|c|c|c|c|c|}
\hline \multirow{2}{*}{ Parameters } & \multicolumn{4}{|c|}{ Prospective patients without asthma $(n=308)$} & \multicolumn{4}{|c|}{ Prospective patients with asthma $(n=95)$} \\
\hline & LC-FVC 95 (36.7\%) & I-FVC 44 (15.6\%) & SC-FVC 169 (47.7\%) & $P$ value & LC-FVC $42(49.5 \%)$ & I-FVC 19 (18.9\%) & SC-FVC 34 (31.6\%) & $P$ value \\
\hline \multicolumn{9}{|l|}{ Demographics } \\
\hline Sex, (\% male) & 92.6 & 95.5 & 90.5 & $0.539^{\mathrm{a}}$ & 78.6 & 94.7 & 88.2 & $0.213^{\mathrm{a}}$ \\
\hline Age, (years) & $66.0 \pm 7.6$ & $64.7 \pm 6.2$ & $65.8 \pm 8.0$ & $0.620^{\mathrm{b}}$ & $62.1 \pm 9.9$ & $63.4 \pm 9.1$ & $61.4 \pm 9.3$ & $0.763^{\mathrm{b}}$ \\
\hline BMI, $\left(\mathrm{kg} / \mathrm{m}^{2}\right)$ & $22.09 \pm 3.09$ & $21.87 \pm 4.29$ & $20.84 \pm 3.33^{\star}$ & $0.011^{\mathrm{c}}$ & $22.15 \pm 3.09$ & $22.66 \pm 3.37$ & $22.34 \pm 3.14$ & $0.844^{\mathrm{C}}$ \\
\hline \multicolumn{9}{|l|}{$\mathrm{FEV}_{1}$ related } \\
\hline $\mathrm{BBD} \mathrm{FEV}_{1},(\mathrm{~L})$ & $1.52 \pm 0.49^{\star *}$ & $1.14 \pm 0.39$ & $0.84 \pm 0.33^{\star \star, t \dagger}$ & $<0.001^{d}$ & $1.63 \pm 0.42^{\star *}$ & $1.16 \pm 0.37$ & $0.83 \pm 0.24^{\star, \dagger \dagger}$ & $<0.001^{d}$ \\
\hline $\mathrm{ABD} \mathrm{FEV}_{1},(\mathrm{~L})$ & $1.66 \pm 0.52^{* *}$ & $1.29 \pm 0.41$ & $0.94 \pm 0.35^{\star \star,+\dagger}$ & $<0.001^{d}$ & $1.83 \pm 0.49^{\star}$ & $1.45 \pm 0.45$ & $0.97 \pm 0.26^{\star, t \dagger}$ & $<0.001^{d}$ \\
\hline $\mathrm{ABD} \mathrm{FEV}_{1},(\%$ Pred $)$ & $61.4 \pm 16.2^{\star \star}$ & $46.6 \pm 13.8$ & $36.1 \pm 12.8^{\star *,+\dagger}$ & $<0.001^{d}$ & $67.9 \pm 16.6^{*}$ & $52.2 \pm 15.4$ & $35.6 \pm 11.3^{\star+十 \dagger}$ & $<0.001^{\mathrm{d}}$ \\
\hline$\triangle \mathrm{FEV}_{1},(\mathrm{~L})$ & $0.14 \pm 0.13^{*}$ & $0.15 \pm 0.10$ & $0.10 \pm 0.09^{*}$ & $0.004^{d}$ & $0.20 \pm 0.18^{*}$ & $0.29 \pm 0.16$ & $0.14 \pm 0.11^{*}$ & $0.002^{d}$ \\
\hline$\Delta \mathrm{FEV}_{1},(\%$ baseline $)$ & $9.5 \pm 8.5^{\star \star}$ & $14.8 \pm 10.5$ & $13.7 \pm 12.0^{\dagger}$ & $0.001^{d}$ & $12.6 \pm 10.6^{\star \star}$ & $26.3 \pm 13.6$ & $18.4 \pm 14.3^{\dagger}$ & $<0.001^{d}$ \\
\hline \multicolumn{9}{|l|}{ FVC related } \\
\hline BBD FVC & $3.23 \pm 0.59^{\star *}$ & $2.63 \pm 0.30$ & $1.95 \pm 0.49^{* *+\dagger}$ & $<0.001^{d}$ & $3.27 \pm 0.58^{\star \star}$ & $2.53 \pm 0.31$ & $1.91 \pm 0.42^{* *, t \dagger}$ & $<0.001^{d}$ \\
\hline ABD FVC & $3.39 \pm 0.62^{*}$ & $3.04 \pm 0.35$ & $2.18 \pm 0.47^{\star *,+\dagger}$ & $<0.001^{d}$ & $3.47 \pm 0.69^{*}$ & $3.15 \pm 0.37$ & $2.24 \pm 0.45^{\star \star, ~ † \dagger}$ & $<0.001^{d}$ \\
\hline ABD FVC (\%Pred) & $98.1 \pm 10.7^{\star \star}$ & $85.7 \pm 5.3$ & $64.4 \pm 10.9^{\star \star,+\dagger}$ & $<0.001^{d}$ & $101.0 \pm 13.7^{\star \star}$ & $88.6 \pm 4.3$ & $63.8 \pm 10.2^{\star \star, \dagger \dagger}$ & $<0.001^{d}$ \\
\hline$\Delta \mathrm{FVC},(\mathrm{L})$ & $0.17 \pm 0.25^{\star \star}$ & $0.41 \pm 0.25$ & $0.23 \pm 0.22^{\star \star, \dagger}$ & $<0.001^{\mathrm{d}}$ & $0.21 \pm 0.26^{\star *}$ & $0.62 \pm 0.26$ & $0.34 \pm 0.28^{*, \dagger}$ & $<0.001^{d}$ \\
\hline$\Delta \mathrm{FVC},(\%$ baseline) & $5.5 \pm 8.3^{* *}$ & $16.0 \pm 10.3$ & $13.7 \pm 14.1^{\dagger \dagger}$ & $<0.001^{d}$ & $6.2 \pm 7.6^{\star \star}$ & $25.0 \pm 12.2$ & $19.1 \pm 16.1^{\dagger \dagger}$ & $<0.001^{d}$ \\
\hline
\end{tabular}

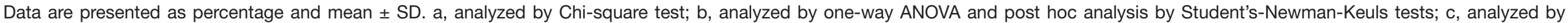

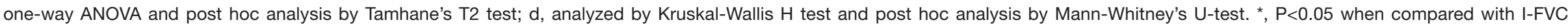

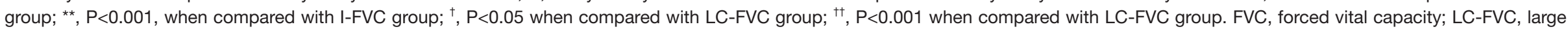

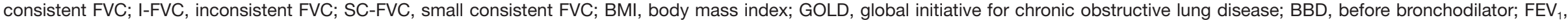
forced expiratory volume in 1 second; ABD, after bronchodilator; $\triangle$, absolute change relative to baseline; Pred, predicted.

Table S3 Comorbidities of 403 prospective patients classified by FVC

\begin{tabular}{|c|c|c|c|c|}
\hline Parameters & LC-FVC ( $n=137, \%)$ & I-FVC $(n=63, \%)$ & SC-FVC $(n=203, \%)$ & $P$ value \\
\hline \multicolumn{5}{|l|}{ Comorbidities } \\
\hline Cor pulmonale & $3(2.2)$ & $1(1.6)$ & $12(5.9)$ & $0.130^{\mathrm{a}}$ \\
\hline OSAS & $1(0.7)$ & $1(1.6)$ & $1(0.5)$ & $0.566^{\mathrm{b}}$ \\
\hline ILD & $0(0.0)$ & $0(0.0)$ & $1(0.5)$ & $1.000^{\mathrm{b}}$ \\
\hline Hypertension & $33(24.1)$ & $18(28.6)$ & $55(27.1)$ & $0.748^{\mathrm{a}}$ \\
\hline $\mathrm{CHD}$ & $13(9.5)$ & $5(7.9)$ & $20(9.9)$ & $0.901^{a}$ \\
\hline Diabetes mellitus & $10(7.3)$ & $3(4.8)$ & $13(6.4)$ & $0.794^{a}$ \\
\hline Anxiety/depression & $2(1.5)$ & $0(0.0)$ & $2(1.0)$ & $1.000^{b}$ \\
\hline Osteoporosis & $6(4.4)$ & $1(1.6)$ & $5(2.5)$ & $0.520^{\mathrm{b}}$ \\
\hline GER & $1(0.7)$ & $0(0.0)$ & $2(1.0)$ & $1.000^{\mathrm{b}}$ \\
\hline
\end{tabular}

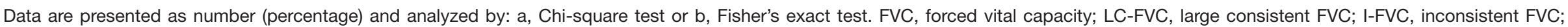
SC-FVC, small consistent FVC; OSAS, obstructive sleep apnea syndrome; ILD, interstitial lung disease; CHD, coronary heart disease; GER, gastroesophageal reflux. 